\title{
Comparison of transverse roughness of the outer surfaces of thin-walled components manufactured using various by milling CAM software
}

\author{
Peter Michalik $^{1}$, Jozef Zajac ${ }^{2}$, Michal Hatala ${ }^{3}$, Dušan Mital ${ }^{4}$, Lukazs \\ Nowakowski ${ }^{5}$
}

The article deals with the measurement and comparison of transverse roughness of the outer surfaces of thin-walled components made of aluminium alloy ENAW2007. The components were manufactured using three CAM applications. Creo 2.0, WorkNC and Autodesk Inventor HSM 2016 to the CNC machining centre VMC 650 Pinnacle S. Roughness was measured by a measuring device Mitutoyo SJ 400. The milling tool has been used with a diameter of $10 \mathrm{~mm}$. Cutting conditions were constant for all three CAM applications. Transverse roughness was measured at six locations milled parts. At the same time for each software to be evaluated time of production of the program and the number of mouse clicks.

Keywords: transverse roughness, thin walled component, aluminium, CAM software.

\section{Introduction}

At present, technical engineering industry belongs to the largest industrial production unit comprising large and technologically demanding structural components. Among structurally challenging components encountered increasingly in technical practice include thin-walled components of various kinds. Today production using advanced CNC machine tools or canters is necessary depending on the requirements of the engineering industry. Comparing these machines with conventional machine has plenty of technological operations using a variety of tools and the use of several tools simultaneously. The long-term direction of development has become a production process automation across all manufacturing sectors, bringing with it a multitude of benefits increase labour productivity, which results in lowering the cost of production.

Numerically controlled machines are the high degree of automation and flexibility to adapt to changes in production. Construction of CNC machine consists of modular structure that allows instant and easy adjustment of the production line, thereby meeting customer requirements. Software measurement cycles automati-

1 TU Kosice, FMT with a seat in Presov, 080 01, Bayerova, Slovakia 2 TU Kosice, FMT with a seat in Presov, 080 01, Bayerova, Slovakia 3 TU Kosice, FMT with a seat in Presov, 080 01, Bayerova, Slovakia 4 TU Kosice, FMT with a seat in Presov, 080 01, Bayerova, Slovakia 5 Politechnika Świętokrzyska, Katedra Technologii Mechanicznej i Metrologii, Aleja Tysiąclecia Państwa Polskiego 7, 25314 Kielce 
cally compensates current length and diameter of tools to calculate the position and rotation angle of the workpiece size and distribution of allowances for machining whose dimensional inaccuracies. CNC machines have become part of every manufacturing company that wants to provide high quality products.

By control systems that include today's CNC machine tools, we are able to create programs when using subroutine can create different shaped parts. Current systems allow not only shop programming, programming in ISO code, STEP programming, but programming using CAD / CAM system [1].

The rapid development of machine production in recent years necessitates rapid implementation of modern engineering technologies and ever higher demands on accuracy and quality of production as well as the function of the thin walled components. Research on surface quality, especially dimensionally thin parts is still in development, given the fact that the production of such components using new technologies, tools and instruments [2].

Thin-walled parts can most use in the automotive, aerospace and energy industries. These are progressing by leaps and bounds, therefore, the accuracy of these used parts also depends on their further development. Direct definition of thinwalled components is not yet given, among the essential characteristics include thin high walls used in a variety of shapes. The main use of these components is to replace the original parts lighter thin-walled components with sufficient strength and the same functionality. The use of these components results in an overall weight reduction of structural units, thereby reducing a number of factors such as production costs, installation time and many more [3].

As a natural border between the workpiece and the environment we represent the surface of industrial parts and workpieces. Actual machined parts surface is defined as a set of characteristic features of a workpiece that describe the international ISO standards. We cannot assume that the machined surface has only mechanical in nature, but actually represents the electromechanical we workpiece surface [4].

The mode of the program production for a concrete component is affected by, the shape of a component itself,

hardware and software design level for programming, operator's prior experience and skills, the type of the control system of a CNC machine, the technical equipment of a CNC machine [5].

Çolak et al. designed and optimized to sophisticated, multi-axis milling centers Therefore data, such as the surface roughness, cutting parameters and dynamic cutting behavior are very helpful, especially when they are computationally produced, by artificial intelligent techniques. They predicted of surface roughness using mathematical equations. They studied gene expression programming method is used for predicting surface roughness of milling surface with related to cutting parameters. Cutting speed, feed and depth of cut of end milling operations are collected for predicting surface roughness. End of the study a linear equation they predicted for surface roughness related to experimental study [6].

Seguy et al. examined the link between chatter instability and surface roughness evolution for thin wall milling. Firstly, the linear stability lobes theory for the thin wall milling optimisation was used. Then, in order to consider the modal in- 
teractions, an explicit numerical model was developed. The resulting nonlinear system of delay differential equations is solved by numerical integration. The model takes into account the coupling mode, the modal shape, the fact that the tool may leave the cut and the ploughing effect. Dedicated experiments are carried out in order to confirm this modelling. This paper presents surface roughness and chatter frequency measurements. The stability lobes are validated by thin wall milling. Finally, the modal behaviour and the mode coupling give a new interpretation of the complex surface finish deterioration often observed during thin wall milling [7].

Jahan et al. studied the average surface roughness value $(\mathrm{Ra})$ for Aluminum after ball end milling operation has been measured. 84 experiments have been conducted varying cutter axis inclination angle ( $\varphi$ degree), spindle speed (S rpm), feed rate (fy $\mathrm{mm} / \mathrm{min}$ ), radial depth of cut (fx $\mathrm{mm}$ ) and axial depth of cut ( $\mathrm{t} \mathrm{mm}$ ) in order to fi nd $\mathrm{Ra}$. This data has been divided into two sets on a random basis. 68 data sets have been used for training different ANFIS model for Ra prediction. 16 test data sets have been used to validate the models. Better ANFIS model has been selected based on the minimum value of root mean square error (RMSE) which is constructed with three Gaussian membership functions (gaussMF) for each inputs and a linear membership function for output. The Selected ANFIS model has been compared with theoretical model and Response Surface Methodology (RSM). This comparison is done based on RMSE and mean absolute percentage error (MAPE). The comparison shows that the selected ANFIS model gives better result for training and testing data. Here ANFIS model has been used further for predicting surface roughness of a typical die made by ball end milling operation. An algorithm was developed to determine the feasible solutions for the cutting parameters in order to obtain a desired surface roughness for the three dimensional die. This algorithm was used to show how a near optimal combination of machining parameters can be determined for a targeted level of surface finish [8].

Gulpak et al. predicted compensation strategies for the combination of thermal effects and residual stresses. This work presents a new concept for the development of such compensation strategies for face milling of steel. In this research the effects of machining induced residual stresses (source stresses) are described by effective source stresses. They can be calculated directly from the distortion of machined specimens and represent the distortion potential of the face milling process for a given set of machining parameters. This procedure enables a full mathematical description of workpiece deformations due to source stresses. Numerical studies have proven a feasible utilisation of experimentally obtained source stresses as input for finite element- simulations [9]. 


\section{Material, manufacturing and measurement}

Dimension of produced thin walled component see in Figure 1. The work piece was made of duralumin ENAW2007. It has a good workability. For experiment are following short-circuit admittance parameters were to be employed: cutting depth (DOC) $1 \mathrm{~mm}$. For each CAM software application was used new intermediate work piece and the new milling cutter. For the manufacture of thin wall parts may also be used Hadfield steel [10] technologies. The cutting tests were carried out on a 3-axis milling center Pinnacle VMC 650S with control system [11] Fanuc Figure 2, with a $4860 \mathrm{rpm}$ spindle, feed $860 \mathrm{~mm} \mathrm{~min}^{-1}$. The tool was a CBN cylindrical end mill HM MG10 HX P 15358.300 with four cutting plates, $10 \mathrm{~mm}$ diameter. Helix angle of inclination $\lambda=55^{\circ}$ angle, rake angle $\gamma=10^{\circ}$ and length of the mill tool $\mathrm{L}=72 \mathrm{~mm}$. Before the measurement traverse roughness on the thin walled component it is necessary to measure a calibration sample of Figure 3 . If the measured values are within the acceptable range of values it is necessary roughness measuring device Mitutoyo SJ 400 and the calibrate control measurement performed again. Measuring of surface roughness Figure 4 was realized on measuring device Mitutoyo on the out place 1, 2, 3, 4, 5, 6. After measuring the transverse roughness on the thin-walled component part at position 1 has been rotated image component of the measured roughness on the place 2 and 3 Figure 5.

\section{CAM software for produced CNC program}

CAD model of part was saved in STEP (*.step) format [12]. Environments of different CAM software solutions are showed on further figures. Selection tool milling of thin walled component in Creo we see in the Figure 6. Selection conturs for milling of thin walled component in Autodesk Inventor Professional HSM PRO 2016 we see in the Figure 7. Simulation milling of thin walled component in WorkNC we see in the Figure 8

\subsection{Comparison and evaluation of creating of CNC programs with use of different CAM software}

Prior to comparison of creation of CNC programs in environment of different software solution it is necessary to determine the categories and values that will be observed, measured and compared in order to make the final result objective and true.

With this paper following values were selected for evaluation purposes: 
Number of mouse clicks while programming the particular operations,

$>$ Time necessary for programs creation and completion of particular technological operations.

Measuring was started with first click on the icon of the program and stopped with complete and usable NC program created. Time measuring was realized between first and last mouse click. Figure 9 shows total time. Necessary for part programming in seconds. The shortest time for creating CNC program was measured for Autodesk Inventor HSM PRO 2016 was 98 second. Thanks to low number of necessary clicks. Second place took WorkNC G3 21.06 with 153 second. The longest time program was measured for Creo 2.0 because of complicated use of working windows.

While setting particular technological operations, roads of tool and cutting conditions it is necessary to use the mouse clicks many times for selecting of actions, orders. Figure 10 provides information on total click amount for selected technological operations.

Measuring was started with first click on the icon of the program and stopped with complete and usable NC program created. Time measuring was realized between first and last mouse click. Figure 9 shows total time.

Necessary for part programming in seconds. The shortest time for creating CNC program was measured for Autodesk Inventor HSM PRO 2016 was 98 second. Thanks to low number of necessary clicks. Second place took WorkNC G3 21.06 with 153 second. The longest time program was measured for Creo 2.0 because of complicated use of working windows.

While setting particular technological operations, roads of tool and cutting conditions it is necessary to use the mouse clicks many times for selecting of actions, orders. Figure 10 provides information on total click amount for selected technological operations.

The shortest number of click for creating CNC program was measured for Autodesk Inventor HSM PRO 2016 was 98. For WorkNC was 112 click. The longest number of click for creation program was measured for Creo 2.0 because of complicated difficult working environment

\subsection{Evaluation of measured transverse roughness}

Gradually three machined surfaces on thin Fasteners with three CNC programs generated by the CAM applications, Creo 2.0, WorkNC and Autodesk Inventor HSM 2016. On the basis of the measured values of transverse roughness Ra and $\mathrm{Rz}$ was constructed the progress Figure 11. 


\section{Conclusions}

Currently, selection process for the production program for the CNC machine is affected by the following factors, type and the actual shape of parts, level of technical equipment, $\mathrm{CNC}$ machines, the type of control system $\mathrm{CNC}$ machine experience and skills of $\mathrm{CNC}$ machine operator, the level of software and hardware firms.

It can therefore be stated, in practice, the way to create a CNC program selected so as to reduce as optionally eliminate the risk of a crisis situation in the production of components by production planning [13].

On the basis of the measurements of the lower time 128 second of production of the program and the lower number 98 of clicks for the production of thinwalled components was similar recommendations CAM Autodesk Inventor HSM 2016.

According to the values of cross-roughness measured at different CAM software applications were the lowest achieved value for Creo in one place with the value of $\mathrm{Ra}=0.4 \mu \mathrm{m}, \mathrm{R}=2.4 \mu \mathrm{m}$, for WorkNC in place of 4 values of $\mathrm{Ra}=0.22$ $\mu \mathrm{m}, \mathrm{R}=1.4 \mu \mathrm{m}$ for Inventor 6 in place with the values of $\mathrm{Ra}=0.4 \mu \mathrm{m}, \mathrm{R}=2.4$ $\mu \mathrm{m}$. According to the values of cross-roughness measured at different CAM software applications were the highest achieved value for Creo at the point 6 with the value of $\mathrm{Ra}=0.61 \mu \mathrm{m}, \mathrm{R}=3.9 \mu \mathrm{m}$ for WorkNC in one place with the values of $\mathrm{Ra}=0.49 \mu \mathrm{m}, \mathrm{Rz}=3.1 \mu \mathrm{m}$, in the Inventor in place 1 with the values of $\mathrm{Ra}=0.53$ $\mu \mathrm{m}, \mathrm{R}=4.0 \mu \mathrm{m}$.

\section{References}

1] Michalik, P., Zajac, J., Duplák, J., Pivovarník, A.: CAM software products for creation of programs for CNC machining, Lect. Notes Electr. Eng. 141 (2011) 421-425. doi:10.1007/978-3-642-27311-7_56.

[2] Novák-Marcinčin, J., Török, J., Janák, M., Novakova-Marcincinova, L.: Interactive Monitoring of Production Process with Use of Augmented Reality Technology, Appl. Mech. Mater. 616 (n.d.) 19-26. http://www.scientific.net/AMM.616.19... .

[3] Kral, J. et al.: Creation of 3D parametric surfaces in CAD systems., Acta Mech. Slovaca 2008. (n.d.) 223-228.

[4] Duplák, J., Panda, A., Kormoš, M., Pandová, I., Jurko, S.: Evaluation of T-vc dependence for the most commonly used cutting tools, Key Eng. Mater. 663 (n.d.) 278-285.

[5] Michalik, P., Zajac, J., Hatala, M.: Programming CNC Machines Using ComputerAided Manufacturing Software, Adv. Sci. Lett. 19 (2013) 369-373. http://www.ingentaconnect.com/content/asp/asl/2013/00000019/00000002/art00003.

[6] Oğuz Çolak, M.C.K., Kurbanoğlu Cahit, Çolak, O., Kurbanoğlu, C., Kayacan, M.C.: Milling surface roughness prediction using evolutionary programming methods, Mater. Des. 28 (2007) 657-666. doi:10.1016/j.matdes.2005.07.004. 
[7] Seguy, S., Dessein, G., Arnaud, L.: Surface roughness variation of thin wall milling, related to modal interactions, Int. J. Mach. Tools Manuf. 48 (2008) 261-274. doi:10.1016/j.ijmachtools.2007.09.005.

[8] Shahriar Jahan Hossain, N.A.: Surface Roughness Prediction Model for Ball End Milling Operation Using Artifi cial Intelligence, Manag. Sci. Eng. 6 (2012) 41-54. doi:10.3968/j.mse.1913035X20120602.2933.

[9] Gulpak, M., Sölter, J., Brinksmeier, E.: Prediction of shape deviations in face milling of steel, Procedia CIRP. 8 (2013) 15-20. doi:10.1016/j.procir.2013.06.058.

[10] Fedorko, G., Molnár, V., Pribulová, A., Futáš, P., Baricová, D.: The influence of Ni and Cr-content on mechanical properties of Hadfield's steel, in: Met. 2011, Tanger Ostrava, 2011: pp. 1-6.

[11] Cep, R.: et al., Ceramic cutting tool tests with interrupted cut simulator, in: P. of I.C. on I.T. Praha (Ed.), IN-TECH 2010, 2010: pp. 144-148.

[12] Novak-Marcincin, J., Novakova-Marcincinova, L., Barna, J., Janak, M., Application of OF FDM rapid prototyping technology in experimental gearbox development process. (1986).

[13] Balog, M., Knapčiková, L., Husár, J., Plánovanie v strojárskej výrobe, Tribun EU., Brno. ISBN 978-80-263-1078-5, 2016.

\section{Acknowledgements.}

This work is a part of research project VEGA 1/0619/15 and VEGA 1/0492/16. 
Figure 1. Dimension of manufactured component in graphical environment Autodesk Inventor 2016.
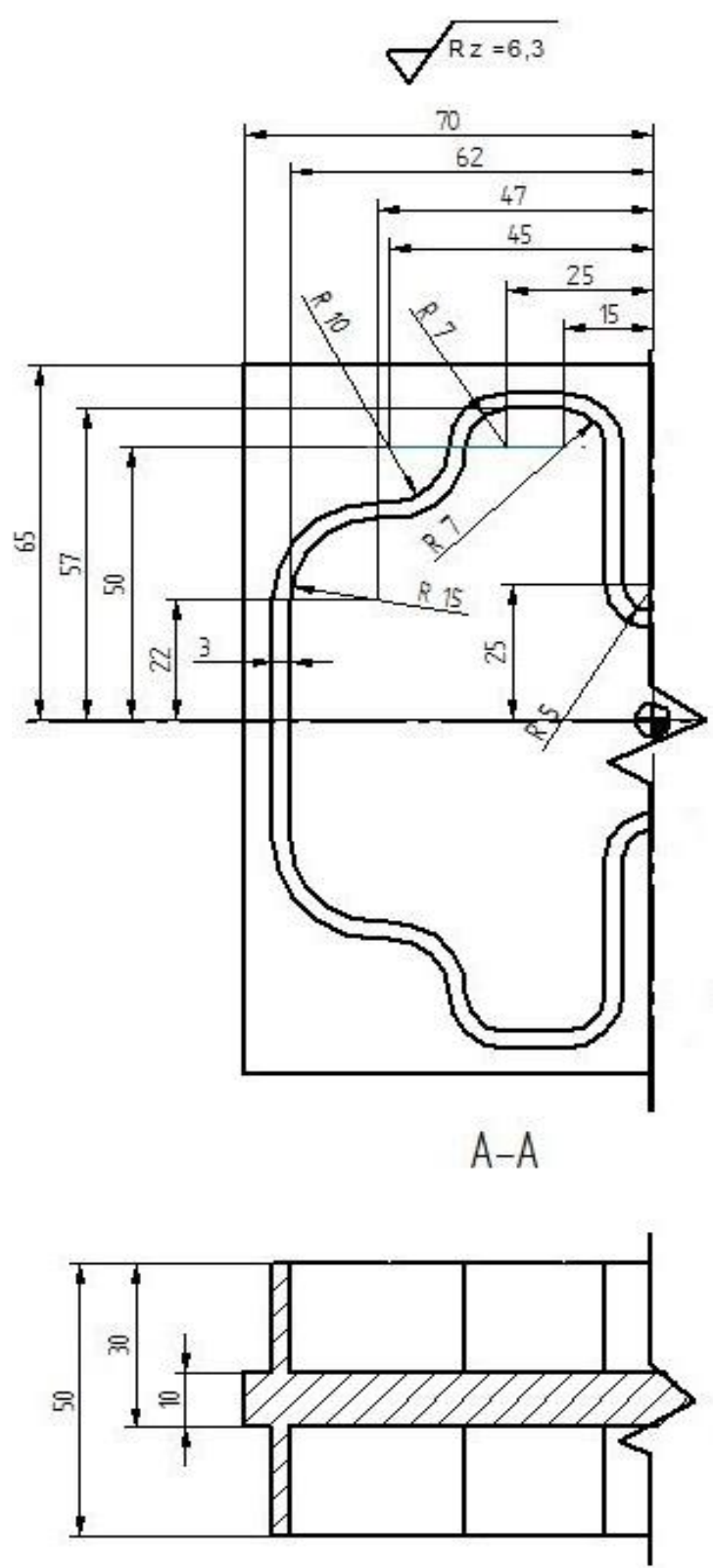
Figure 2. Three axis milling center Pinnacle VMC 650S with manufactured component and milling tool.

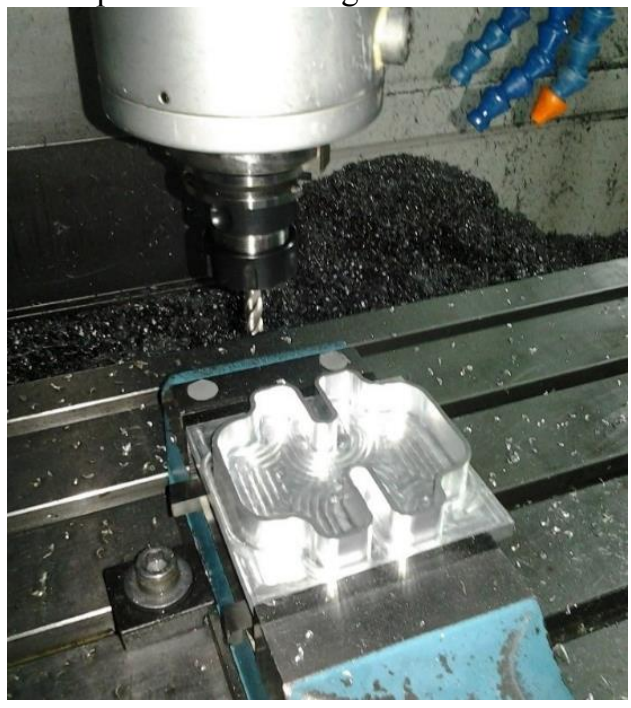


Figure 3. Measurement a calibration sample on the measuring device Mitutoy SJ 400.

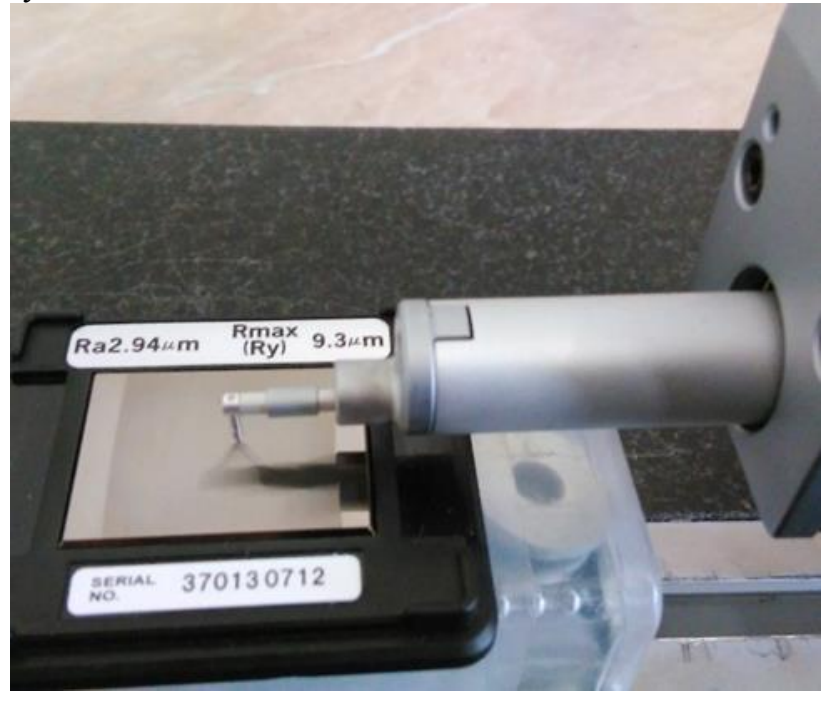

Figure 4. Measurement of traverse roughness on the out place 1

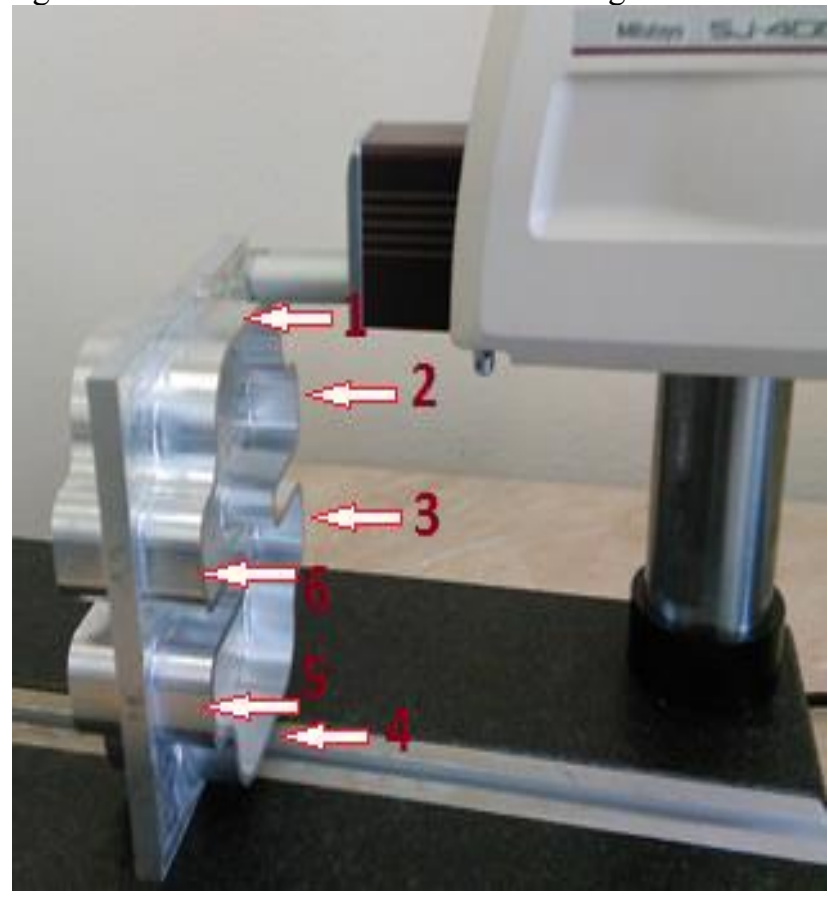


Figure 5. Measurement of traverse roughness on the out place 2 and 3

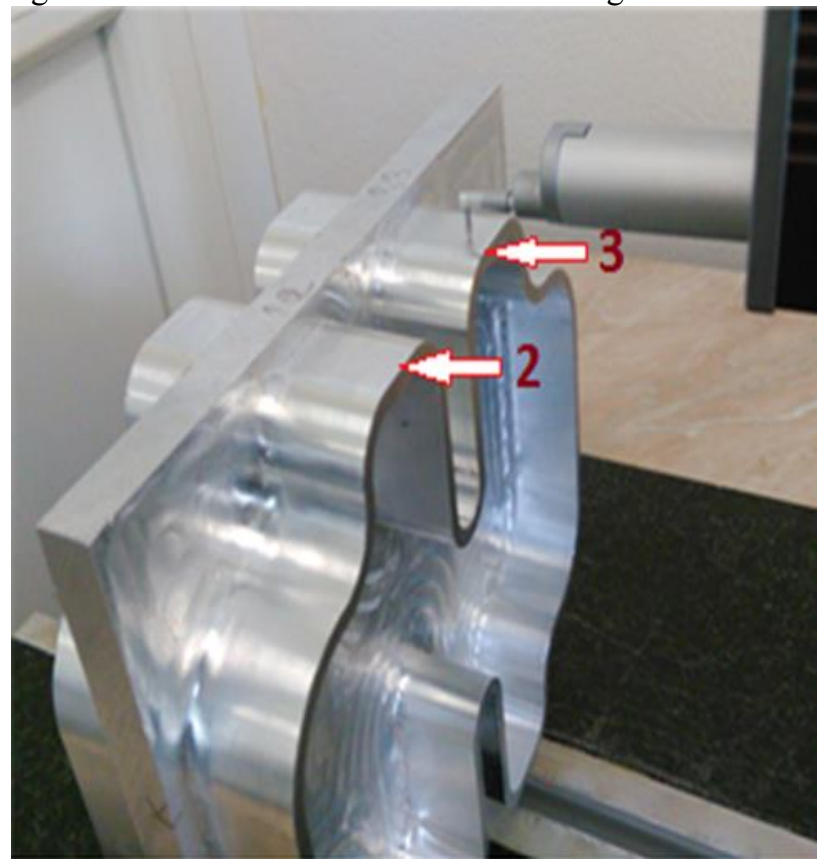

Figure 6. Selection milling tool of thin walled component in Creo

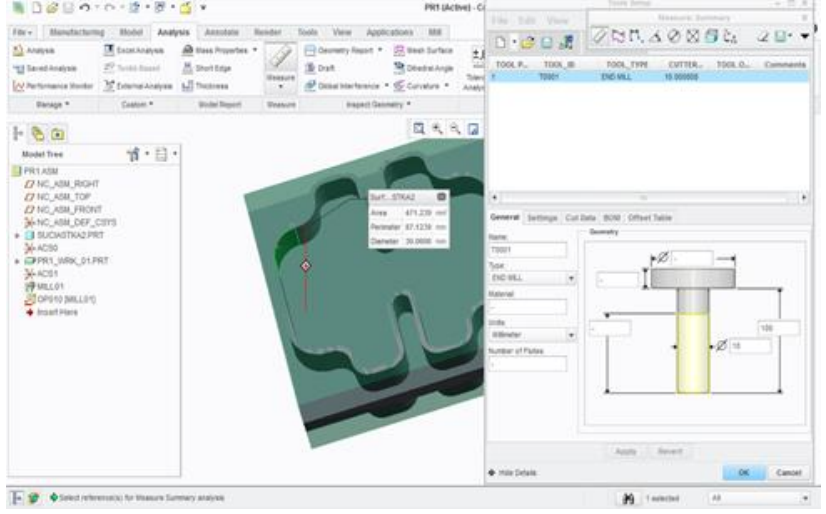


Figure 7. Selection contours for milling of thin walled component in $\mathrm{Au}-$ todesk Inventor Professional HSM PRO 2016

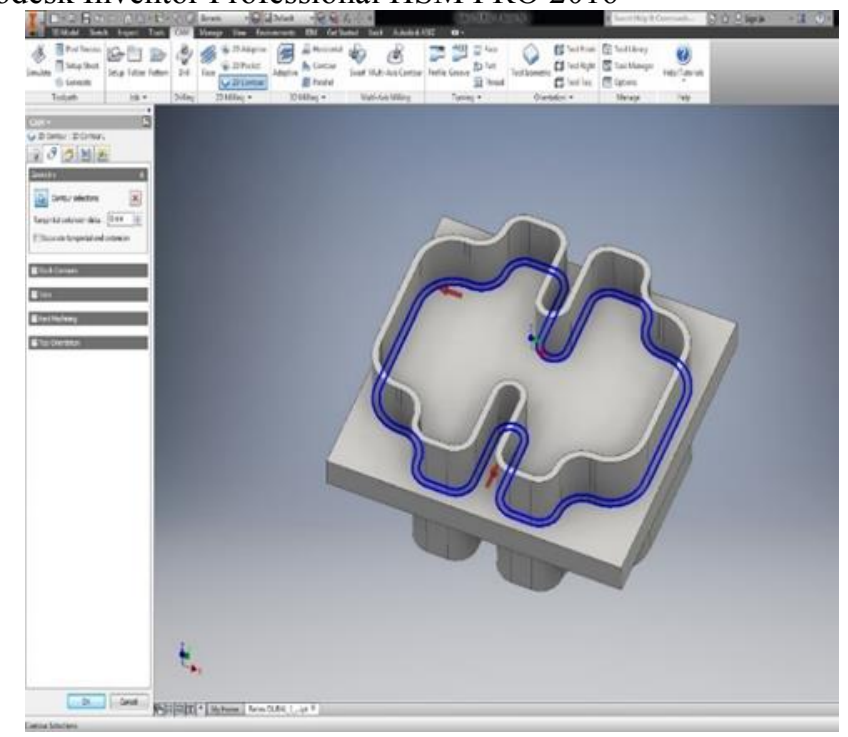

Figure 8. Simulation milling of thin walled component in WorkNC

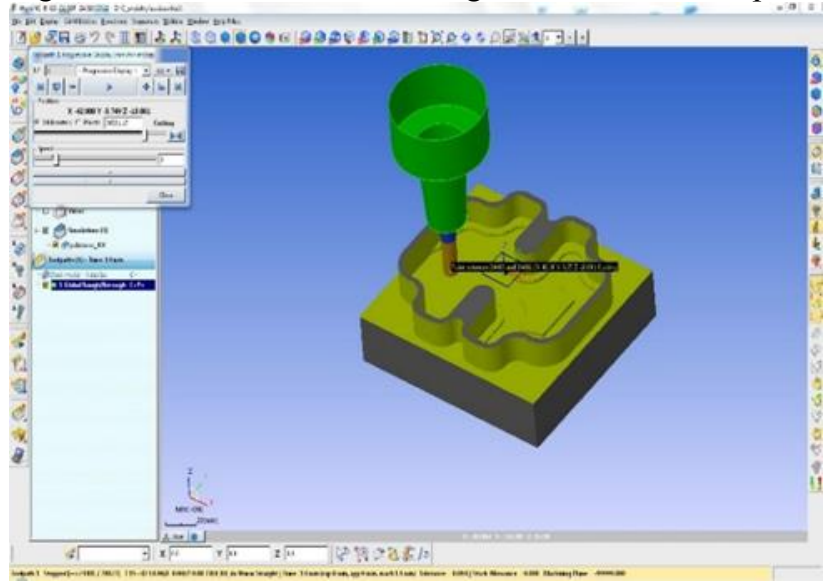


Figure 9. Total click number for necessary creation of CNC program by help Creo, WorkNC and Inventor HSM PRO 2016

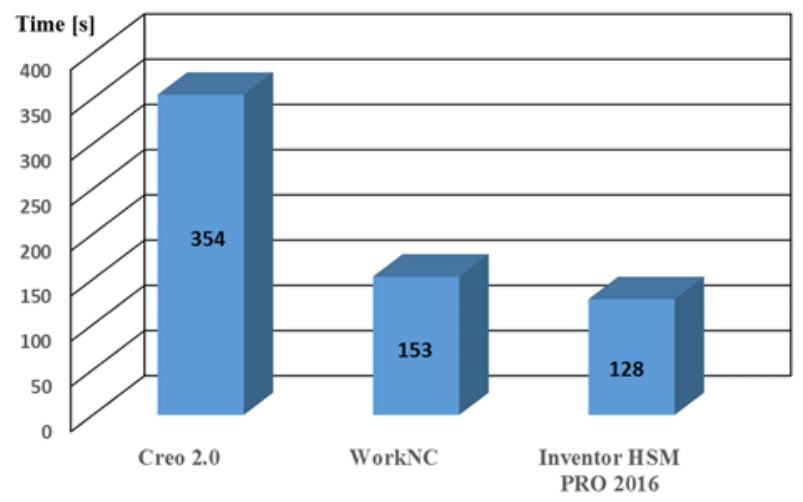

Figure 10. Total programming time for Creo, WorkNC and Inventor

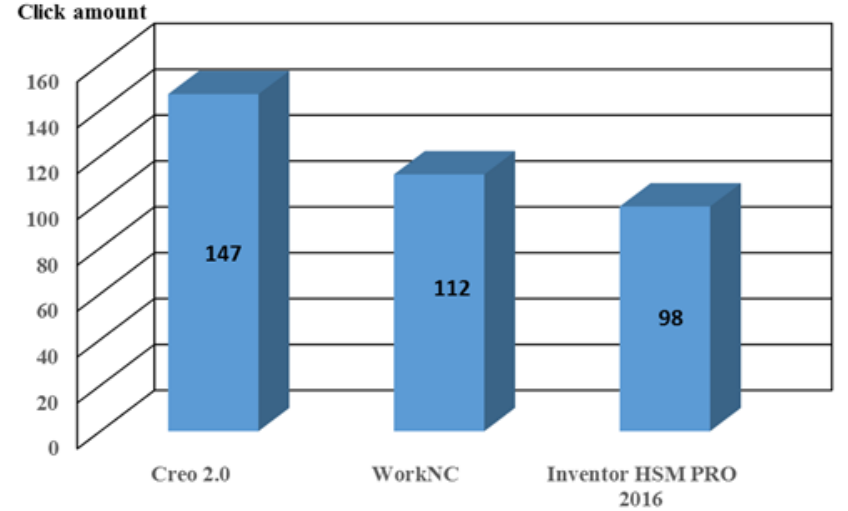


Figure 11. The transverse roughness $\mathrm{Ra}$ and $\mathrm{Rz}$ surface of thin walled component

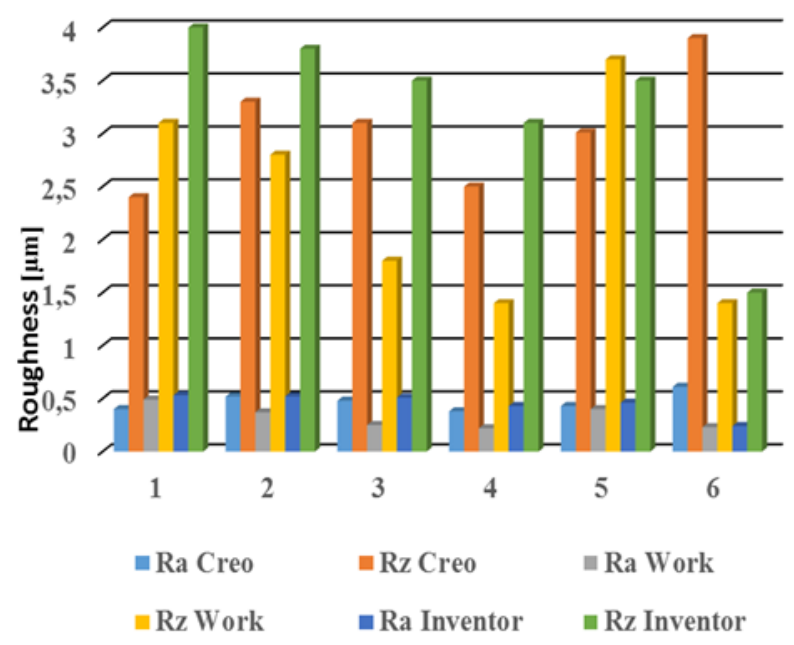

